\title{
Visual-Semiotic Analysis of Brand Marketing with Reference to Contemporary Advertizing Media
}

\author{
Shaista Zakir ${ }^{1}$
}

\begin{abstract}
This research revolves around a thematic content analysis, conducted within a qualitative mode of inquiry. It aims at presenting an account of a visual semiotic examination of contemporary advertising media, through the lens of contribution made by Barthes (1977), a renowned semiotician of the present age. In order to investigate the problem, three of the famous advertisements as frequently broadcasted through contemporary advertizing media, have been selected as the sample of study. The analysis centers on linguistic, coded iconic, and the non-coded iconic messages, conveyed through the selected advertisements. A detailed investigation in this regard revealed that apparently superficial images contained in video advertisements, on the basis of interplay between the signifier and the signified, provide an array of targeted meanings. The conveyed information, besides manifesting a skillful art of representation, seeks to propagate a multitude of themes. The present research is an attempt to elaborate some of the dynamics forming the core of the concerned issues.
\end{abstract}

Keywords: Visual semiotics, brand marketing, advertising media, linguistic message, coded iconic message, non- coded iconic message

\section{Introduction}

People of the modern age live in a semiotic enigma of signs and symbols. Mehmet (1996) truly entitles a human being in a modern world as a 'Homo Semioticus' (p. 41). The humanity in other words, as a matter of fact depends upon "a certain signification or symbolic order", based on "an empire of signs" (Porcar, 2011, p. 21). Recent semiotic research focuses on the role played by signs and symbol with regard to all possible facets of life in general. The investigation has given rise to a number of innovative and productive avenues never conceived of before.

Modern tradition, characterizing the realm of semiotics, has been pioneered by a renowned Swiss linguist Ferdinand De Saussure (1857-1913). Saussure viewed language to be "a system of signs", distinguished on the basis of "signifier" vs "signified", required to be studied "synchronically" rather than "diachronically" (Eagleton, 1996, p. 84). He termed the relationship between the signifier and the signified as "signification" (Bainbridge, 2010, p. 194). The comprehensive theory of structuralism provides varying levels of semantic interpretations, each one of the levels emerges into a number of intricate combinations and functions (Stephen, 2000).

Semiotics as a comprehensive zone of inquiry challenges the literal dimensions of interpretations as it "rejects the possibility that we can neutrally represent the way things are" (Chandler, 2007, p. 123). Recent research in the field of semiotics includes theoretical and methodological paradigms, taken from different fields of inquiry including linguistics, anthropology, sociology, psychology, philosophy, education, and anthropology (Chandler, 2007, p. 4). ${ }^{1}$ Dr. Shaista Zakir is Lecturer, Department of English, SBK Women's University Balochistan, Quetta,
ms.shaista.zakir@gmail.com

\begin{tabular}{llll|l}
\hline JISR-MSSE & Volume 12 & Number 2 & July-December 2014 & 91
\end{tabular}


Since 1980s, semiotics has emerged as an integral and commonly recognized part of media based research, with specific reference to the realm of marketing. The researchers like Beasley \& Danesi (2002), Eco (1976), Barthes (1977), Peirce (1931-58) and Fiske (1990), have contributed a lot to the inquiry by presenting many of the prominently influential frameworks and methodical approaches.

The qualitative research under observation revolves around the thematic content analysis of advertisements as its selected samples. It attempts to present a visual semiotic analysis of brand marketing through contemporary advertizing media. By focusing on the visual dimensions of semiotic analyses, it probes into the nature of the ways advertisements are presented, together with a propagation of semantic contents specific to these representations. The samples of the study have been delimited to three advertisements, viewed and analyzed through the lens of Barthes' (1977) analytical model, with specific reference to the linguistic message, the non-coded iconic message (denotation) and the coded iconic message (connotation).

\section{Literature Review}

Within every sphere of inquiry, the efforts put by the pioneers are regarded to be monumentally consequential with respect to further advancements. Similarly, the renowned semioticians around the globe owe their debt to the contributions made by a Swiss linguist Ferdinand De Saussure (1857-1913). Researchers like Barthes (1967), Jameson (1972), Culler (1975), Hawkes (1977), and Eagleton (1999) for instance, categorically maintain that the foundational grounds for modern structuralism lie within the structuralist foundation provided by Saussure. The birth of structuralism is often dated back to the publication of Saussure's Course in General Linguistics (1916). Many of the structuralist ideas were brought together in the lectures delivered by Saussure at the University of Geneva (Lyons, 1981).

Saussure (1966) views sign to be the combination of concept and sound image, a kind of combination that cannot be separated i.e. when he claims:

I propose to retain the word 'signe' (sign)to designate the whole and to replace concept and sound-image respectively by signifié (signified) and significant(signifier); the last two terms have the advantage of indicating the opposition that separates them from each other and from the whole of which they are parts. (p. 67).

The Signifie, according to Saussure (1966) is the aspect of meaning wholly internal to the language system. The Signifiant of a word, according to him results ultimately from the arrangement of differences and uniformities that a particular language system imposes upon the series of sounds.

While elaborating the issue in question, Charles Sanders Peirce, another famous semiotician, focused on three aspects of signs: icon, index, and symbol. In case of Iconic sign according to him, the signifier represents the signified by apparently having a similarity with it. This type of sign is often very important in visual images and is used to convey photographic and diagrammatic themes. The Indexical signs according to him, depict the inherent relationship between signifier and the signified. Indexical signs thus reflect the contiguity or causality e.g. snow can be a sign of fire. The symbolic sign, as viewed by him, represents a 
conventionalized and clearly arbitrary relationship between the signifier and the signified. For example, a balance scale representing a symbol of justice manifests a symbolic sign. Peirce's Contribution proved to be very dominant with reference to the zone of semiotic research. While Saussure regards semiology to be the science studying the role of signs as part of human beings' social facet of vitality, Peirce considers semiotics to be the formal doctrine of signs, having close harmony with logic as a prominent branch of philosophy (Peirce, 1931-58). Peirce's "non deterministic" theory of semiotics holds that although a sign seeks to represent an object, the required effect that is produced by the interpreter of that sign has to have a "prior 'collateral' experience of that object". An interpretation of signs as viewed by Peirce thus is a process that varies amongst individuals, keeping into consideration their specific experiences about life in general (Jappy, 2013, p. 25).

The influence of Peircean tradition is evidenced in semiotic theories promulgated by Eco (1976) in the modern world (Bianchi \& Gieri, 2009). A Theory of Semiotics presented by Eco (1976), is considered to be one of the most important contributions in the field of semiotics. Eco, according to Berger (2010), holds that semiotics pertains to everything that can be considered as a sign "substituting for something else" (p. 11). The notion of meaning, in the field of semiotics, as viewed by Eco (1976), can be interpreted in terms of its being a "cultural unit", having a deep rooted social and historical character (Bianchi \& Gieri, 2009, p. 28). His viewpoint considering perception to be "the primary stage of semiosis", is based fundamentally on Peirce's analyses.

With the development of new trends in electronic and print media during the present century, the field of semiotics has indubitably sought to evince its consequential impact. If we analyze different facets of print and electronic media, i shall be observed that the semiotic technique has been aptly incorporated by both of the mentioned zones. Baudrillard (cited in Perry, 1999), as one of the most important researcher of the modern world in the field of semiotics, has developed the theories of "simulation" and "hyper-reality" to address the issue in detail. Baudrillard, (cited in Cobley, 2001), on the basis of his analyses claims that as a result of a continuous display of signs and images, a kind of "simulation world" has emerged; the sort of world has created a blurred demarcation between the "real" and the "imaginary" influencing the major disciplines like "science", and "philosophy" (p. 59).

The emerging signs create an image of "hyper-reality", which appears to be "more real than actual reality"; "the simulation", in other words, "seems to be more real than the things they simulate" (Berger, 2010, p. 50). The overall practice has resulted in the development of a "consumer culture" within "consumer-crazed societies" in "postmodern" world (p. 50). Beasley \& Danesi (2002), in the same context hold that semiotics aims at making us "filter" the implicitly conveyed meaningful contents and the images which "swarm and flow through us everyday" (p. 31). Here it is important to mention that one of the most significant analytical pursuits dealing with the images in advertisements can be found in the research conducted by Barthes (1977). The images presented in advertisements, according to Barthes (1977) are "frank" and "emphatic in their representations, conveying a deliberate and planned signification. (p. 33). Despite being discontinuous in their structural organization, they present a unified whole of signifieds, giving rise to multidimensional meanings. He argues: “....in advertising the signification of the image is undoubtedly intentional; the signifieds of the advertising message are formed a priori by certain attributes of the product and these signifieds have to be transmitted as clearly as possible" (p. 33). 
Barther elaborates the nature of these images in terms of the following kinds of messages:

i. $\quad$ Linguistic Message

ii. Non coded Iconic Message

iii. Coded Iconic Message

Linguistic Message, according to him, depends upon the code of message. It consists of the brand's name and the verbal account or commentary related to it. It thus includes all forms of verbal texts. Non-coded iconic message deals with the visual image. Within this kind of non-coded message, the photographic image comparably manifests the real objects in such a manner that they convey the literal, denotative meaning of the images. Coded iconic message pertains to the connotations of the picture forming the overall image of a product to be presented. The coded iconic message depends upon the factors like the receiver's culture and social norms, along with his/her aesthetic knowledge. Connotation implies the interaction that occurs when signs meet receivers' feelings and their cultural values (Fiske 1990). The non linguistic signs, as elucidated by Barthes (cited in Fiske, 1990) are so open to a variety of interpretations that they constitute "a floating chain of signifieds" (p. 110).

The historical research in the field of marketing reveals that semiotics became a generally recognized concept of the field during 1980s. A probe into the dominant ideological themes like that of capitalism, materialism, and consumerism makes it explicitly evident that semiotic technique has profoundly been infused into their thematic frameworks. The visual dimension of semiotic application has therefore proved to be an area of prominent inquiry. In the modern world, the persuasive and convincing messages are not transferred to the targeted audience without keeping into consideration the dynamic role played by visual semiotic strategies.

Kress and Leeuwen (2006) while dealing with the issue under consideration, introduce the concepts of visual code or the grammar of visual design. According to them, both visual as well as verbal structures can be utilized for expressing the meaning emerging from specific cultural contexts. The visual rhetoric strategies require meticulous details to be pondered over with reference to the advertisements, encompassing the choice of typography, paratext, accurate placement of the logo, and a relationship between different colors, pictures, and texts. A careful investigation of the slogans as used in modern advertisements reveals that most of them employ code switching, pun, paradox, litotes, hyperbole, metonymy, metaphors, antithesis, ellipsis, and chiasmus. Moreover, the use of appealing adjectives to attract the customer's attention is considered to be an important strategy used by the advertising agencies. The adjectives are used in ads to convey either a 'positive or a negative meaning' (Delin, 2000 , p. 133). The effectiveness of certain colors as another significant aspect of famous advertisements has been analyzed by the many of the postmodern researchers who provide a detailed overview of the processes through which colors influence the targeted viewers (Beasley \& Danesi, 2002). Along with an application of all above mentioned attributes, the presence of famous celebrities like movie stars, cricketers, beauty icons renowned chefs, cooking experts, celebrated religious personnel, fake or real professionals including doctors, engineers, scientists, and chemists prove to ascertain the validity of manufactured products.

An interesting realm of inquiry pertains to the ways advertisements manipulate and thereupon direct human perception in a specific way. Mick (1986), for instance views that when a viewer is confronted by an advertisement showing a woman who provides her family with a specific

\begin{tabular}{l|llll}
\hline 94 & July-December 2014 & Volume 12 & Number 2 & JISR-MSSE
\end{tabular}


nutritionally balanced meal per day, he can infer that the woman is a good mother, thereof instantiating the culturally acquired rule that all women performing the same act are actually the good mothers. Such sorts of techniques attract the consumers, thereby seeking to generate and develop the targeted perceptions in the viewers' minds (Kress, 2010, Abdelal \& Sasi, 2014).

The overall activity in this context seems to encompass three fundamental notions formulating visual meaning: the signs themselves, their organization into systems and the contexts in which they appear (Crow, 2003). By focusing on a skillful use of "signs and colors" the advertisers ensure the popularity of the targeted brands among the consumers (Najafian \& Kitabi, 2011, p. 73). With the help of advertisements, brands generate the conceptions we hold in our minds as observers about a specific commodity and the way it differs from the other competing commodities. The notion of brands, thus, revolves around the connotative dimensions of its meanings "based on perceived and distinctive qualities a product has" (p. 79).

The semiotic -specific investigations in the modern world comprehend "structuralist semiotic analysis", "critical discourse analysis", and "content analysis", mostly conducted within a qualitative mode of inquiry (Chandler, 2007, p. 222). Keeping into consideration the comprehensive nature of the field, the integrated approaches, including conceptual frameworks from all of the mentioned kinds of analyses have also been in practice, broadening the scope of the pertinent research. However, despite magnanimous investigations conducted by many of the famous theorists, some of the researchers lament the fact that analyses of visual or non verbal messages have been discounted. The inadequacy of modern inquiry resulting in an insufficiently integrated research has thus been highlighted by the thinkers of the present age. Detailed exploration and surveys are therefore needed to be incorporated so as to expand the horizons of modern research in this regard.

\section{Methodology and Data Analysis}

As mentioned earlier, the present research is based on the visual semiotic analysis of brand marketing with reference to contemporary advertising media. In order to conduct the mentioned analysis, the qualitative mode of inquiry has been preferred, based on the thematic content analysis of three of the famous Pakistani advertisement, selected as the samples of the study. The brands presented through the selected advertisements have been mentioned as follows:
a. Pantene (a hair care product)
b. Pepsi (a famous carbonated soft drink)
c. Everyday (a dairy tea whitener)

In order to analyze the visual semiotic dimensions of the selected samples for study Barthes' (1977) analytical model termed as The Rhetoric of the Image has been employed as the theoretical framework. Barthes' (1977) explication with regard to the issue provides a detailed overview of the functions performed by visual images in propagating the targeted meanings. The analysis centers on a deliberate signification conveyed through the videos of advertisements under observation. It primarily addresses the linguistic, coded iconic message and the noncoded iconic messages related to the display of video -based images in the advertisements. The linguistic messages address the linguistic dimensions of advertisements. The coded iconic

\begin{tabular}{lll|l}
\hline JISR-MSSE & Volume 12 & Number 2 & July-December 2014
\end{tabular}


messages describe the connotative meanings, while the non coded iconic messages aim at elaborating the denotative angles of advertisements under analysis. A detailed account of thematic content analysis has been presented as follows:

\subsection{Thematic Content Analysis of the Selected Samples for the Present Study}

\subsubsection{Advertisement No.1: Pantene (PantenePK, 2014)}

The Linguistic Message

The main crux of the advertisement seems to lie within the verbal commentary initiated by a famous celebrity icon, as soon as the advertisement begins. Her verbal description has been translated as follows:

Pantene makes an ordinary day seem extraordinary. It is not difficult to look pretty while performing as a heroine in a drama. The whole team of stylists is there to make me appear lovely and attractive. But life in reality is not a 'drama'.......! In everyday life routine, one cannot have the stylists' team around all the time ........ Only Pantene is there with me to make my look appealing. Pantene makes my hair strong and nice looking........ Though I am not a singer, yet when the shiny swinging locks of my adorable hair sway around, I really feel like humming....... Shine Pantene.....!

A close linguistic analysis of the advertisement reveals some of the important semiotic dimensions. The brand's name is a Coinage which has not yet been codified in the lexicon. The name appears above the logo, written in a way all its graphemes are capitalized, so as to attract the viewer's attention. The accurate placement of brand's emblem along with its name makes it easily intelligible. The entire verbal commentary is characterized by the use of an affably simple, straightforward, girlie, and informal manner of expression, code switching, transliteration, and persuasively figurative language. The overall warmth and tenderness of linguistic expression as used in the advertisement makes a listener feel as if he/she is listening to a close friend in an informal and friendly social setting. The viewers seem to own the product, rather than considering it to be an ostentatious object beyond the reach of common mass.

\section{The Non-Coded Iconic Message}

The famous female model, and a celebrated beauty icon has been represented as a pretty, confident and happy soul, cascading her dark black, gorgeous hair from time to time while giving listeners an account of her daily routine with the pleasant impact of the product on her hair. The scene changes suddenly and the viewer is made to see a ramp of a fashion show where the model is presented with a bouquet of adorable flowers (which a viewer infers, might have been given by one of her admirers).

The main place where the female model has shown to be sitting, appears to be an exotic blend of modern and postmodern style of interior decoration, adorned with unusual and costly furniture, pricey items of embellishment and luxury, giving a sense of lavishness and extravagance. The advertisement ends with the model's deliberately emphatic yet implicit recommendation to prefer the product favored by her. The scene is immediately followed by an animated view of the product's logo.

\begin{tabular}{l|llll}
\hline 96 & July-December 2014 & Volume 12 & Number 2 & JISR-MSSE
\end{tabular}




\section{The Coded Iconic Message}

The coded iconic message as we know depends upon the connotative dimensions of advertisement. If we concentrate on the advertisement in question, we shall realize that it carries an array of connotative meanings, producing what Barthes refers to as a floating chain of signifieds.

The female character as shown in the advertisement seems to be a perfect epitome of feminine beauty in accordance with the criteria set by the conventional ideology in this regard. She is a smart, pretty, fair skinned, rich, well dressed, and glamorous young lady, liked by everybody around her. Besides, she has been demonstrated as a contented, cheerful, and confident being living in a sort of an imaginary fairyland, where she is the only centre of attraction because of her immense loveliness and beauty. The close analysis of the advertisement reveals as if the entire visual activity has been aimed at captivating a girl's sense of imagination. While seeing the advertisement, a girl somewhere deep within her heart, desires to own all of the qualities owned by the heroine of the advertisement encompassing elegance, grace ,charm ,contentment and true love. The advertisement at the same time intends to target the opposite gender's intrinsic longing to have the fair lass. Both of the gender's perceptions have thus been mesmerized by the astute working of the advertisement-campaign .The focus of all activity has ultimately been made to revolve around the fact whereby the fair lady of the ad, (enchanted by the spell of her fairyland), acquires all of the desired qualities a girl can ever dream of, because of her exclusive choice to use the specific hair care product (i.e. Pantene).

\subsubsection{Advertisement No.2: Pepsi (User, 2014)}

\section{The Linguistic Message}

The Trademark of the product is a coinage, written in a stylized lowercase on the cricketball so as to grab the attention of viewers (especially the young ardent lovers of cricket). At the same time, a question has been posed whereby the viewers is required to conjecture the ownership of the only beverage claimed on by the two well known heroes. The question presented in this regard has been demonstrated in Roman Urdu other than the conventional Perso-Arabic Script .The use of Roman Urdu script is a popular technique used by different media, related to the realm of information technology, in the modern world. The language used throughout the ad, consists of few dialogues, characterized by the use of slangs, simple language, code-switching, pun, witticism, taunts, and ridicules, making the overall impression amusing and entertaining.

\section{The Non-Coded Iconic Message}

The logo of a carbonated soft drink, i.e. Pepsi, presented in the advertisement, has been inscribed on a cricket- ball having three colors: (red, white, and blue respectively). The advertisement seems to be a blend of modern and ancient themes, merged together in an amusing way. The two famous cricketers named Shahid Afridi and Misbah ul Haq are shown to be up against unusual circumstances. The advertisement starts with a scene showing Afridi gaining consciousness on a sea shore. All of a sudden Misbah appears from somewhere and gives him a helping hand. A series of adventure begins consequently and both of the cricketers 
are constrained to spend their lives, (full of exciting activities) in an unknown and uninhabited island. Both of the young men engage themselves in the task of fulfilling the basic requirements of life, arguing, and squabbling over the only Pepsi which neither of them wants to be given to the other member irrespective of their sense of cooperation and support throughout. Once, while disputing over the treasured product, both of them see a wooden box imprinted with Pepsi's logo, floating in the water near the shore. Both of the friends hurriedly run towards the box in order to have as much of the beverages as possible. To their disappointment, however, the box turns out to be empty, containing a muddy surface with a crab inside, moving over the stones. Let down by an utter regret, the two heroes come back to find a pretty lady, dressed up in precious jewels, drinking Pepsi, flashing a triumphant smile ,teasing both of the cricketers.

\section{The Coded Iconic Message}

The advertisement under examination is rich in coded iconic messages. The two famous handsome young men along with a pretty young lady have been selected as the main characters of the advertisement. The beauty, youth, fame, popularity, and recognition have once again been cashed in by the advertizing agency to maximize the demand of its product. The advertisement revolves around an adventurous mission of two young men grasping the attention of the viewers by their comic heroism .It indirectly conveys the message that the celebrities and apparently adorable and stylish young ones prefer Pepsi to any other drink. The admirers of Pepsi, in other words, have thus been delineated as true heroes. A spirit of mystery, allure, fascination, amusement, love, and thrill has been set at poles throughout the advertisement.

A close examination of the commercial exposes the fact that the young enthusiasts of cricket in general and the cricketers in particular, have been targeted by the advertising agency. While watching the advertisement, when the viewers amusingly observes the two renowned international heroes fighting for Pepsi, then, along with an amusing sense of delightfulness, they subconsciously relate the above mentioned heroic sensations of adventure and charm to the product itself. The presence of pretty young lass on the island adds to the enchantment of the activity going on. She is pretty and attractive young lady, wearing costly dress and high priced jewelry. Accustomed by the unnatural scenes like that, a viewer does not bother about the presence of well dressed, fashionable young lass on an uninhabited far off island. The young cricketers' preference with regard to Pepsi, other than the girl's beauty, makes the product more valuable in the eyes of viewers. All one concentrates on is the charm and charisma created by the artificially built, breathtaking situations with Pepsi being presented as the younger beings' drink that cannot be sacrificed at any cost.

\subsubsection{Advertisement No.3: Everyday Tea Whitener (ACELYNX, 2014)}

\section{The Linguistic Message}

The advertisement carries Nestle's English trademark with an Urdu slogan written in Arabic script. The linguistic content of the advertisement revolves around the informal conversation going on between the family members, marked by the use of simple language ,mild family squabbles, pleasantly ironic remarks, code switching, ellipsis, paradox and metaphorical expressions. All of the dialogues follow an informal style of discourse, having an uncomplicated and straightforward expression in terms of phrasal, clausal, and sentential structures. The

\begin{tabular}{l|llll}
\hline 98 & July-December 2014 & Volume 12 & Number 2 & JISR-MSSE
\end{tabular}


advertising jingle appearing in the final scene, like many other advertisements, follows a Roman-Urdu style of writing.

The Non-Coded Iconic Message

The advertisement begins with a scene presenting family members sitting in a lawn outside their adorably lavish and luxurious home when a graceful and charming young lady comes out of the house serving tea to the family members including her husband, a father in law (both of them reading newspapers) and a mother in law. All of the family members are dressed up in elegantly fashionable attire. The young daughter in law informs her husband of her intention to go to a parlor. Hearing that, the mother in law expresses her desire to accompany her. The father in law amusingly taunts the middle aged mother in law for being in competition with her young daughter in law in her grooming preferences. The daughter in law comes up with a witty remark by maintaining that the mother in law is in competition with him rather (i.e. with the father in law). A lighter tone is added to the environment and all of the family members exchange smiles among themselves. The scene changes and the viewer is made to see a clean and aristocratically built kitchen where the young lady has been shown happily making tea with a verbal commentary going on in the background which can be translated as:

"As your peculiar style makes every relationship special, in the same way, "Everyday" gives tea a very special flavor"

The overall process of making tea is marked by animated accessories and play of colors giving an appealing charm to the overall activity.

The scene changes again, a viewer sees the remaining part of the advertisement. The middle aged mother in law indirectly expresses her delight at the witty remark put forward by the young lady by saying that she really enjoyed herself. The old man gives an impression of confusion; the middle aged woman describes her point further by holding that what she implied was actually the enjoyment experienced, while taking tea made by the daughter in law. The old man pretends an embarrassing look and the whole family bursts out laughing.

\section{The Coded Iconic Message}

The coded iconic message as promulgated by the advertisement connotatively entails that the product (i.e. Everyday tea whitener) is a choice of the elegant members from the elite class. The friendly home environment adds to the influential effect of the ad, implying as if the product with its magical effect binds the family together. Dressed in light blue ( the color of product's packing), the pretty, sociable, affable and good natured young lady has been demonstrated as a responsible daughter in law and a loving wife, concerned about the health of her family members. She thus is an angel in the house, liked equally by all around her. Her good nature, however, does not alone suffice the purpose ,the magic has rather been added by the product itself. The viewer is thus made to think that the product can be a choice of all those families who want to have as friendly and as genial a relationship amongst themselves as the one demonstrated in the ad. 


\section{Conclusion and Recommendations}

An examination of the above mentioned advertisements, making use of Barthes' (1977) framework of analysis truly reveals that visual representations in advertisements, have an influential role in the lives of their viewers. A viewer is sensitive to the linguistic, non coded and the coded iconic messages of the advertisement and is consequently influenced by its alluring charm. During the process one is utterly oblivious of the ideologies working in the background, the deliberate representation of elite class, preference for the good looking young men and women, the company's concealed motives, artificiality of the scenes, and an explicit cultural disparity. All one remembers is but an unknown sense of fascination, thrill, and excitement, along with an unconscious attempt to be like the beings presented and to possess the products owned by them.

The semiotic dynamics of the advertisements convey a number of denotative and connotative meanings, giving rise to innumerable signifieds with specific interpretations in terms of informational matter presented explicity as well as implicitly. The themes of beauty, elitism, excitement, boldness, thrill, extravagance, confidence, lavishness, grace, elegance, stylishness, courtesy, and sophistication have been emphatically linked to all of the targeted products. The resulting simulations and the simulacra, undoubtedly direct the viewers' perceptions towards the required angles, in an astounding manner, thereby making the advertising agencies achieve their semiotic objectives. Further research in this regard can be carried out in variety of ways within different research paradigms and tools chosen for the purpose. A detailed account of psychoanalytical, Marxist, pos-structuralist and purely cognitive-narratological dimensions of visual semiotics, can be analyzed with an emphasis on the ways whereby the advertisements in an imperceptible manner target and thereupon influence their viewers.

\section{References}

Abdelal, N, M. \& Sase, A, S. (2014). Advertisement Analysis: A Comparative Critical Study. Advances in Language and Literary studies.5 (6), 254-259.

Acelynx. (2014, December, 15). Nestle EVERYDAY - TUM MAIN HAY KUCH KHAAS. Retrieved from: http://www.youtube.com/watch? $\mathrm{v}=\mathrm{xf6s} \_$AbLmiU

Bainbridge, J. (2010). Visual Law: The Changing Signifiers of Law in Popular Visual Culture. In Anne Wagner \& Jan M. Broekman. (Ed.), Prospects of Legal Semiotics (pp.193215). New York: Springer.

Barthes, R. (1967). Elements of Semiology. London: Jonathan cape.

Barthes, R. (1977 ). Image, Music, Text. London: Fontana press.

Beasley, R. \& Danesi, M. (2002). Persuasive Signs: the Semiotics of Advertising. Berlin: Moutor de Gruyter. 
Berger, A, A. (2010). The Objects of Affection: Semiotics and Consumer Culture. New York: Palgrave Macmillan.

Bianchi, C. \& Gieri M. ( 2009). Eco's Semiotic Theory. In Peter Bondanella (Ed.). New Essays on Umberto Eco. New York: Cambridge University Press.

Chandler, D. (2007). Semiotics: The Basics. Routledge: New York.

Cobley, P. (2001). The Routledge Companion to Semiotics and Linguistics. Routledge: London.

Crow, D. (2003).Visible Signs. New York: Watson-Guptill Publications.

Culler, J. (1975) Structuralist Poetics, London: Routledge \& Kegan Paul.

Delin, A. (2000). The Language of Everyday Life. London: Sage.

Dyer, G. (1990): Advertising as Communication. London: Routledge.

Eagleton, T.(1996). Literary Theory: An Introduction, Oxford: Blackwell.

Eco, U. (1976) A Theory of Semiotics. Bloomington: Indiana University Press

Fiske, J. (1990): Introduction to Communication Studies. London: Routledge

Harris, R. (1987): Reading Saussure: A Critical Commentary on the Course in General Linguistics London: Duckworth.

Hawkes, T.(1977). Structuralism and Semiotics, London: Methuen

Hofstede, G. \& Hofstede, G. (2005): Cultures and Organizations: Software of the Mind. New York: McGraw-Hill.

Jameson, F. (1972). Marxism and Form: Twentieth Century Dialectical Theories of Literature, Princeton: Princeton University Press.

Jappy, T. (2013). Introduction to Peircean Visual Semiotics. New York: Bloomsbury.

Kihlstrom, J. F., \& Cantor, N. (2000). Social intelligence. In R. J. Sternberg (Ed.), Handbook of human intelligence. New York: Cambridge University Press.

Kress, G. (2010). Multimodality: A Social Semiotic Approach to Contemporary Communication. London: Routlege.

Kress, G \& Leeuwen, T.V. (2006). Reading Images, the Grammar of Visual Design (2nd ed.). London: Routledge.

Lester, P. (2006). Visual Communication: Images with Messages: Cengage Learning. 
Lyons, J. (1981). Language and Linguistics. UK: Cambridge University Press.

Martin, B. (2000) Dictionary of Semiotics. London: Cassell Publications,

Mick, D .G. (1986). Consumer Research and Semiotics: Exploring the Morphology of Signs, Symbols and Significance', Journal of Consumer Research 13(2): 196-213.

Najafian, M. \& Ketabi, S. (2011). Advertising Social Semiotic Representation: A Critical approach. International Journal of Industrial Marketing. 1(1), 63-78.

PantenePK. (2014, December, 15). Mahnoor Baloch| Pantene Shampoo TVC - YouTube. Retrieved from: http://www.youtube.com/watch?v=rdC_NRBdSSY

Peirce, C. S. (1931-58). Collected papers of Charles Sanders Peirce (Vol. 1-8). Cambridge, MA: Harvard University Press.

Perry, N. (1998). Hyperreality and Global Culture. New York: Routledge.

Porcar, C. (2011). Sign and Meaning: A Semiotic Approach to Communication. Journal of Communication and Culture. 1(1), 20-29.

Mehmet, R. (1996). Homo-Semioticus. Istanbul:Yap? Kredi Yay?nlar?.

Rose, G. (2001). Visual Methodologies. London: Sage Publications Ltd.

Saussure, F. D. (1966). A Course in General Linguistics (W. Baskin, Trans.) .New York: McGraw-Hill.

Stephen, M. (2000). English Literature: A Student Guide, London: Longman.

Sutherland, M. (1993). Advertising and The Mind Of The Consumer. Allen \& Unwin

User. A. (2014, December, 15). Pepsi Afridi-Misbah Beach TV Commercial 2012. Retrieved from: http://tune.pk/video/1658252/pepsi-afridi-misbah-beach-tv-commercial-2012

\begin{tabular}{l|l}
\hline 102 & July-December 2014
\end{tabular}

Volume 12

Number 2

JISR-MSSE 